\title{
SPECTROPHOTOMETRIC ANALYSIS AND FRACTURE RESISTANCE OF SUPER AND ULTRA TRANSLUCENCY ZIRCONIA VERSUS LITHIUM DISILICAET GLASS CERAMICS
}

\author{
Sara Telyani ${ }^{*}$, Esam Osman ${ }^{* *}$, Mohammad Rayyan ${ }^{* * *}$, Ehab A. Farghaly ${ }^{* * * *}$ and Ghada E Hamza ${ }^{* * * * *}$
}

\begin{abstract}
Purpose: To compare the translucency and fracture resistance of crowns fabricated using 3 different ceramic materials.

Materials and Methods: A human maxillary right premolar was prepared to a $0.4 \mathrm{~mm}$ chamfer finish line, with 6 degrees convergence angle and $1.5 \mathrm{~mm}$ occlusal clearance. Using industrial silicon (Body Double, Smooth-On), a mold was poured to construct 20 identical resin dies. After scanning the resin dies, 10 ultratranslucency monolith zirconia (UTZ) crowns and 10 supertranslucency monolith zirconia (STZ) crowns were milled and sintered according to manufacturer directions. The same premolar was further prepared to a $0.6 \mathrm{~mm}$ chamfer finish line, and 10 resin dies were constructed and scanned using same technique to perform ten IPS e.max crowns which were milled accordingly and sintered according to manufacturer directions. All specimens were tested for translucency using spectrophotometer (Nippon Densmoku industries). All specimens were then subjected to fracture resistance test using universal testing machine (The Testometric Company Limited), at cross head speed $0.5 \mathrm{~mm} / \mathrm{min}$, with force direction 90 degrees angle to the occlusal table, at the central fossa.
\end{abstract}

Results: Viewing the mean of translucency between studied groups, group STZ scored the highest TP (21.03 \pm 4.41$)$, followed by group UTZ (19.42 \pm 4.31$)$, then group IPS e.max (19.29 \pm 4.49$)$. Regarding mean fracture strength, group UTZ scored the highest value $(1009.91 \pm 360.20 \mathrm{~N})$ followed by group STZ $(847.18 \pm 329.92 \mathrm{~N})$ then group IPS e.max $(821.51 \pm 175.69 \mathrm{~N})$. One-way ANOVA revealed no significant difference between groups in either translucency $(\mathrm{P}=0.621)$ or fracture strength $(\mathrm{P}=0.328)$.

Conclusions: The two tested hybrid ceramics could present an acceptable treatment option for fabricating monolith ceramic crowns. There was no significant difference in either translucency or fracture resistance between all tested groups.

KEY WORDS: IPS e.max, ultratranslucency zirconia, supertranslucency zirconia, translucency, fracture resistance.

* Clinical instructor Oral Rehabilitation Sciences, Beirut Arab University, Faculty of Dentistry

** Professor of Dental Biomaterials, Beirut Arab University, Faculty of Dentistry

***Associate Professor of Prosthodontics, Beirut Arab University, Faculty of Dentistry, Assistant Professor of Fixed Prosthodontics, Faculty of Dentistry, Misr University for Science and Technology, Cairo, Egypt

****Lecturer of Fixed Prosthodontics, Faculty of Dentistry, Misr University for Science and Technology, Cairo, Egypt ***** Lecturer of Fixed and Removable Prosthodontics Department, Oral and Dental Research Division, National

Research Center, Cairo, Egypt. 


\section{INTRODUCTION}

Translucency is one of the main pillars in material selection for the esthetic zone. Its quantitative values could aid the clinician in perfect treatment planning for esthetic cases. ${ }^{(1)}$

Ceramics are strong candidate as an esthetic material fulfilling biocompatibility, mechanical properties, depth of color and translucency. IPS e.max was first introduced as a core material that should be veneered by feldspathic porcelain for maximum esthetics. But due to its superior mechanical properties (400 MPa), it was used as monolith crowns and veneers. It was the golden standard for veneers and crowns in the esthetic zone. Unfortunately, it is monolithic and its translucency is inferior to feldspathic porcelain. Recently, many ceramic materials with different mechanical and optical properties were introduced into the dental field. Esthetics of a prosthesis depends on many factors including color and translucency. Clinicians should be aware of the quality and the characteristics of these materials so they would be able to select better materials for successful clinical use ${ }^{(2)}$.

Zirconia started as a strong substitute to metal in bi-layered restorations. It offered high mechanical properties, and was called "the ceramic steel". Unfortunately, it began with a dull cold white color prevented it from being used in esthetic areas ${ }^{(3)}$. To provide high strength and improved esthetics, zirconia has been used as a core material; porcelain is then fused to the outer surface. Zirconia has been shown to be more translucent than metal substructures when ceramic is fused to the outer surface.

The veneering porcelain is more translucent and allow the zirconia core material color to show. However, a common problem with veneered zirconia oxide compared to metal-ceramic crowns is an increased fracture rate, possibly caused by the mismatch of the coefficients of thermal expansion, surface grinding, inadequate core design, or overloading. To reduce the risk of veneering fracture and to simplify the procedures, manufacturers have recently marketed monolithic zirconia restorations.

Recently, a new generation of zirconia were presented; the ultra-translucent (UTZ) and the super-translucent (STZ). They were promised by their manufacturer to surpass e-max in both strength and translucency. A question worth answering: is whether the translucency of UTZ and STZ can match the translucency of that of famous IPS e.max (EM) ?

The hypothesis of this study was that the new super and ultratranslucency zirconia will surpass IPS e.max in both fracture strength and translucency.

\section{MATERIALS AND METHOD}

A sound natural maxillary right second premolar was mounted in the center of $10 \times 10 \times 20 \mathrm{~mm}$ block, with base of block parallel to occlusal surface of tooth. The premolar was prepared, by dental parallelometer, to a $0.4 \mathrm{~mm}$ chamfer finish line, using round-end taper diamond bur with guiding pin, and $1.5 \mathrm{~mm}$ occlusal reduction was done using round-edge wheel stone. A silicon index containing 10 molds was constructed. Resin material was mixed according to manufacturer directions and poured using vibrator to fabricate 20 resin dies 10 for UTZ group and, 10 for STZ group. Using dental parallelometer, the thickness of finish line was increased to $0.6 \mathrm{~mm}$ on the natural premolar fixed inside block. Following the same procedure conducted in the previous two groups, 10 resin dies were fabricated for EM group.

All dies were individually digitally scanned and a CAD model was generated for each specimen. Groups UTZ and STZ were milled with a dry milling machine from corresponding zirconia blocks. For group EM, crowns were milled in a wet milling machine. All specimens were sintered according to manufacturer's direction. Each crown was finished and polished using manufacturer's supplied kit, ultrasonically cleaned, dried and 
assigned individually to its corresponding tooth. All crowns were tried on their corresponding teeth, margins stability and integrity was checked using light microscope.

Translucency parameter represents the color difference between a material of uniform thickness over a black and a white background, and corresponds directly to a common visual assessment of translucency ${ }^{(4)}$. CIELAB color parameters (Commission Internationale de l'Eclairage,1986), has been largely used to compare translucency among materials ${ }^{(5)}$. The translucency parameter (TP) values were calculated by using the following equation:

\section{$T P=\left[(L b-L w)^{2}+(a b-a w)^{2}+(b b-b w)^{2}\right]^{1 / 2}$}

where " $b$ " and "w" refer to color coordinates over the black and white backgrounds, respectively.

All resin dies were colored using water-based black color. The specimens and the spectrophotometer were always in the same position during all the measurements, by using a custom-made tooth positioning framework to standardize the measurements. The specimens were properly cleaned then the resin dies were colored again using water-based white color (Fig. 1). The specimens were then tested using spectrophotometer. The translucency values were calculated by using the previous equation.

The inner surface of EM group were etched using 5\% Hydrofluoric gel for 20 seconds and rinsed. After though, silane coupling agent was applied on intaglio surface for 60 seconds, then thinned and air dried. The inner surface of UTZ and STZ groups were air particle abraded, using 50 $\mu$ alumina particles at 60 degrees angle and distance of $1 \mathrm{~cm}$ at 2.8 bar for 20 seconds. All crowns were placed in ultrasonic solution and left to dry. The intaglio surface was then painted by ceramic primer (clearfill ceramic primer kuraray), using microbrush and thinned out by means of gentle oil-free brusts of air.

Dual cure resin cement was applied on the inner surface of crown, then all crowns were positioned

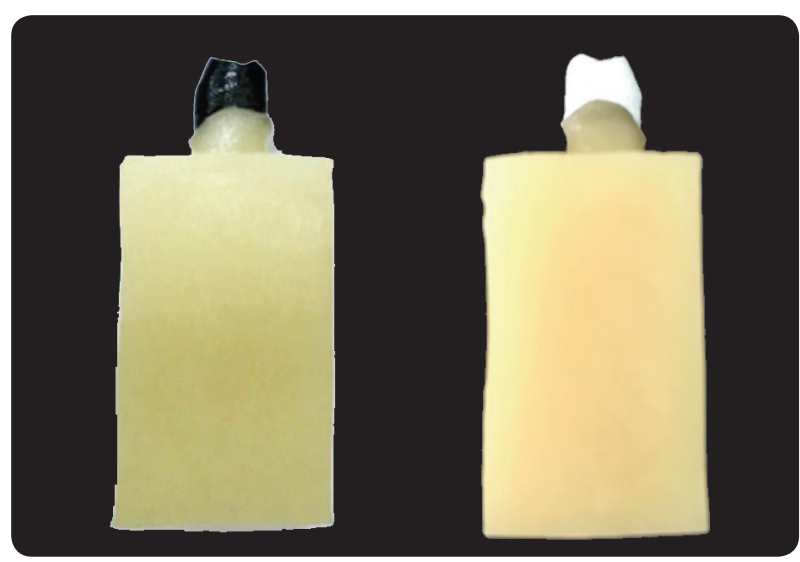

Fig. (1) Colored resin dies.

on its corresponding resin dies. Final curing by Led cure was done 10 seconds twice for labial and palatal surfaces. All the specimens were stored in distilled water at room temperature for 48 hours. All specimens were then thermo-cycled for 1000 cycles between $5^{\circ} \mathrm{C}$ and $55^{\circ} \mathrm{C}$ with dwell time of 30 seconds at each temperature.

All specimens were individually mounted onto the lower fixed compartment of a universal testing machine parallel to the long axis of the tooth, and subjected to load at their central fossae by roundend metallic rod on 4 layers of aluminum foil to evenly distribute applied forces, at cross head speed $0.5 \mathrm{~mm} / \mathrm{min}$ until failure which was defined by sudden drop of force values.

Results were recorded, tabulated, and statistically analyzed. Numerical data were explored for normality distribution of data, using KolmogorovSmirnov test.

\section{RESULTS}

Viewing the translucency mean results of groups (Table 1), STZ scored the highest TP (21.03) followed by UTZ (19.42) and the least was EM (19.29). Descriptive statistics including mean and standard deviation values were computed for each group. There was no significant difference in translucency between the ceramic types. 
TABLE (1) Descriptive statistics of translucency between studied groups

\begin{tabular}{|c|c|c|c|c|c|c|}
\hline & Ceramic Type & N & Mean & Std. Deviation & Min & Max \\
\hline \multirow{4}{*}{ Translucency } & UTZ & 10 & 19.42 & 4.31 & 12.92 & 28.40 \\
\cline { 2 - 7 } & STZ & 10 & 21.03 & 4.41 & 15.95 & 31.72 \\
\cline { 2 - 7 } & $\mathbf{E M}$ & 10 & 19.29 & 4.49 & 10.97 & 26.82 \\
\hline
\end{tabular}

Regarding fracture resistance (Table 2), the mean results; UTZ scored the highest fracture resistance $(1009.91 \mathrm{~N})$ followed by STZ $(847.18 \mathrm{~N})$ and the lowest was EM $(821.51 \mathrm{~N})$. There was no significant difference in fracture resistance between the tested groups.

TABLE (2) Descriptive statistics of fracture resistance.

\begin{tabular}{|c|c|c|c|c|c|c|}
\hline & Ceramic Type & N & Mean & Std. Deviation & Min & Max \\
\hline \multirow{3}{*}{$\begin{array}{c}\text { Fracture Resistance } \\
\text { (in Newton) }\end{array}$} & UTZ & 10 & 1009.91 & 360.20 & 342.6 & 1389 \\
\cline { 2 - 7 } & STZ & 10 & 847.18 & 329.92 & 260.2 & 1334 \\
\cline { 2 - 7 } & $\mathrm{EM}$ & 10 & 821.51 & 175.69 & 639.9 & 1224 \\
\hline
\end{tabular}

\section{DISCUSSION}

Proper selection of ceramic material that fulfil perfectly the dental client's esthetic demand considered a serious matter. The selection should be based on a lot of criteria in order to survive in the complicated harsh oral environment. Translucency and optimum mechanical properties were paramount factors in that selection.

A number of steps were conducted in the methodology for sake of standardization, and to perfectly answer the proposed research question. Premolars were chosen to be tested rather than incisors, because they fit more to monolith treatment plan than anterior teeth. Monolith design was selected to avoid false results obtained from delamination fracture in bilayerd assembly ${ }^{(6)}$.

The use of natural teeth closely resembles the clinical condition, although, each extracted tooth has its own history and its own fracture resistance dictated by anatomy and hard tissue thickness.
That's why resin dies were used in this study, to eliminate the variability in natural teeth. On top of that resin dies have modules of elasticity closely resembles that of natural teeth ${ }^{(7)}$.

Flexural strength as well as E-modulus and Poisson's ratio of die materials has been considered important for the fracture resistance of all-ceramic crowns ${ }^{(8,9,10)}$. It has been suggested that a low E-modulus of the die material (10-14 GPa), as compared to ceramics tested (350-700GPa), may be more accurate in terms of deformation, since it will closer match the value of human dentin. In the present study, the elastic properties were in the range of those reported in earlier studies on resinbased polymer materials ${ }^{(8,9)}$. The Poisson's ratio of the die material in use $(0.43)$ was found to be close to that of wet dentin $(0.38-0.45)^{(12)}$.

Full crowns were constructed instead of discs in this study to simulate the actual clinical situation. A $0.4 \mathrm{~mm}$ chamfer finish line was prepared for zirconia specimens ${ }^{(13)}$, and $0.6 \mathrm{~mm}$ for IPS e.max 
specimens ${ }^{(14)}$, as dictated by the manufacturer as the optimum thickness needed for both types of the ceramics used. It is neither too thin to reveal the color of the underlying tooth structure, nor too thick to be more conservative and protect the amount of the remaining tooth structure.

Monolith crowns were used for both ceramics to avoid inaccuracies in results generated from possible chipping or delamination of veneering ceramics. As a result of incompatibility, firing protocol discrepancies, or due to inconsistency in coefficient of thermal expansion between core and veneering material $^{(15)}$.

Viewing the translucency results, both types of zirconia scored higher mean delta $\mathrm{E}$ than IPSe.max. This is translated as a higher translucency because, the more color difference read between the black and the white backgrounds, the more translucent is the material. Adding Yettria to zirconia seemed beneficial to the translucency but unfortunately it affected its fracture resistance.

One way ANOVA revealed no significant difference in translucency between tested ceramic groups. This finding is opposite to earlier results stated by Baldissara, et al, ${ }^{(15)}$ 2010, who found that the lithium disilicate glass ceramic showed significantly greater translucency than zirconiabased core materials. This may be attributed to the fact that they use different types of zirconia with lower translucency that that used in the current study. As translucency is highly variable based on manufacturer formulation, production process, and laboratory sintering times and temperatures.

As comparing the fracture resistance mean, both zirconia materials scored higher mean fracture resistance than IPS e.max. This result was expected as it is well known that the zirconia surpasses the IPSe.max in its mechanical properties ${ }^{(16)}$. Several factors may influence the fracture strength of ceramic restoration such as microstructure, fabrication technique, preparation design and luting method.
However, these variations are likely to exist in clinical situations as well. Therefore, the range of values can be considered relevant as it was related to actual performance. Although fracture strength values of the tested groups were in the limit of manufacturer's specification of each material. Early failure due to weak cementation between ceramic and resin dies did not occur in this study, but most of the fractures were in the ceramic restorations themselves rather than the resin dies.

Recently there is a favorable shift of permanent dental restorative materials toward matching the translucency and mechanical properties of the tooth structure rather than materials with very high fracture strength values. The tested zirconia ceramics seem to be a viable treatment option in restoration demanding translucency and high esthetic and good mechanical properties.

The suggested hypothesis was rejected. The ultratranslucency and supertranslucency zirconia didn't surpass IPS e.max in both translucency and fracture strength.

\section{CONCLUSIONS}

Within the limitations of the study, the following could be concluded:

1) The two tested hybrid ceramics could present an acceptable treatment option for fabricating monolith ceramic crowns.

2) There was no significant difference in either translucency or fracture resistance between all tested groups.

\section{REFERENCES}

1. Sravanthi Y, Ramani YV, Rathod AM, Ram SM, Turakhia H. (2015)The comparativeevaluation of the translucency of crowns fabricated with three differentall-ceramic materials: an in vitro study. J Clin Diagn Res. Feb; 9(2):ZC30-4.

2. Altamimi AM, Tripodakis AP, Eliades G, Hirayama H.(2014). Comparison of fracture resistance and fracture 
characterization of bilayered zirconia/fluorapatite and monolithic lithium disilicate all ceramic crowns. Int $\mathrm{J}$ Esthet Dent. Spring;9(1):98-110.

3. Kelly JR, Tesk JA, Sorensen JA.(1995). Failure of allceramic fixed partial dentures in vitro and in vivo: analysis and modeling. J Dent Res. Jun;74(6):1253-8.

4. Johnston M, Reisbick MH.(1997). Color and translucency changes during and after curing of esthetic restorative materials. Dental Materials. March vol.13(2):89-97.

5. Paravina RD, Ontiveros JC, Powers JM.(2004).Accelerated aging effects on color and translucency of bleaching-shade composites. J Esthet Restor Dent.16(2):117-26.

6. Lin CL, Chang YH, Pai CA.(2011). Evaluation of failure risks in ceramic restorations for endodontically treated premolar with MOD preparation. Dent Mater. May; 27(5):431-8.

7. Cho L, Song H, Koak J, Heo S. (2002). Marginal accuracy and fracture strength ofceromer/fiber-reinforced composite crowns: effect of variations in preparationdesign. J Prosthet Dent. Oct; 88(4):388-95.

8. Scherrer SS, de Rijk WG.(1993). The fracture resistance of all-ceramic crowns onsupporting structures with different elastic moduli. Int J Prosthodont. Sep-Oct;6(5):462-7.

9. Yucel MT, Yondem I, Aykent F, Eraslan O. (2012) Influence of the supporting die structures on the fracture strength of all- ceramic materials. Clin Oral Investig.Aug;16(4):1105-10.

10. Kelly JR, Tesk JA, Sorensen JA.(1995). Failure of allceramic fixed partial dentures in vitro and in vivo: analysis and modeling. J Dent Res. Jun; 74(6):1253-8.

11. Kinney JH, Marshall SJ, Marshall GW. (2003). The mechanical properties of humandentin: a critical review and re-evaluation of the dental literature. Crit Rev Oral Biol Med.14(1):13-29.

12. Beuer F, Aggstaller H, Edelhoff D, Gernet W. (2008) Effect of preparation design onthe fracture resistance of zirconia crown copings. Dent Mater J. May;27(3):362-7.

13. Reich S, Wichmann M, Nkenke E, Proeschel P. (2005). Clinical fit of all-ceramicthree-unit fixed partial dentures, generated with three different CAD/CAMsystems. Eur J Oral Sci. Apr;113(2):174-9.

14. Malkondu O, Tinastepe N, Akan E, Kazzazoglu E. (2016). An overview of monolithic zirconia in dentistry. Journal biotechnology and biotechnological equipment. Aug; 8(1):54-78.

15. Baldissara P, Llukacej A, Ciocca L, Valandro FL, Scotti R. (2010). Translucency ofzirconia copings made with different CAD/CAM systems. J Prosthet Dent. Jul; 104(1):6-12

16. Schwindling FS, Rues S, Schmitter M. (2017). Fracture resistance of glazed, full-contour ZLS incisor crowns. J Prosthodont Res. Jan 19. 